Military Technical College

Kobry Elkobbah,

Cairo, Egypt

May 25-27,2010

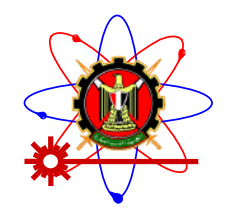

$5^{\text {th }}$ International Conference on Mathematics and Engineering Physics (ICMEP-5)

\title{
EM-22
}

\section{Optimization of End- Milling Operation Using Response Surface Methodology in Combination with Simulated Annealing}

\author{
Prof. Mohamed H. Rasmy, Ass. Prof. M. H. Gadallah
}

\begin{abstract}
:
In this paper we describe a methodology that includes the complementary use of response surface methodology (RSM) and simulated annealing algorithms(SAA).In this methodology we use response surface methodology (RSM) through 12 experiments for 3 input (depth of cut- cutting speed and feed rate) with 3 levels for each to develop an approximating model for end-milling process. This approximating model is based on observed data from the process. Then we use simulated annealing algorithms to solve this model within the range of the factors (depth of cut- cutting speed and feed rate) to predict the optimal value of surface roughness and cutting condition.
\end{abstract}

$\underline{\text { Keywords: }}$ response surface methodology - simulated annealing - surface roughness

\section{Introduction:}

The production of mechanical part is tight to tolerance and with optimal productivity is one of the main challenges of modern production technique.

Machining is very common operation to obtainable finished part of complex shapes with high precision. The tuning of the optimal solution must be as effective as possible. The optimization by means of simulation is an important improvement. It allows getting the optimal cutting condition for a given operation without interrupting the production process. (7) To perform experimented test many aspects of the machining process can be studied by simulation. One of the most developed domains is the prediction of cutting condition or prediction of surface roughness of work pieces to optimize the process.

The main objective in this work is how to predict surface roughness by using new technique RSM in combination with Simulated Annealing.

RSM may not be accurate enough in modeling highly nonlinear behaviors as this process and also the improvements to the accuracy of the RSM are limited.(3) There for it is important to investigate other approximation techniques such as simulated annealing and study how they could be used to complement the RSM.(7) 


\section{2- Response Surface Methodology (RSM)}

\section{2-1: linear regression models:}

The practical application of RSM is necessary to develop an approximating model for the response surface the underlying true response surface is typically droved by some unknown physical mechanism. The approximating model is based on observed data from the process system and is an empirical model.

Multiple regressions is a collection of statistical techniques useful for building the types of empirical model required in RSM

Now we wish to develop on empirical model relating to the surface roughness:

1- Depth of cut

2- Cutting speed

3- Feed rate

A second - order response surface model (3) that might describe this relationship is:-

$\mathrm{Y}=\mathrm{B}_{\mathrm{o}}+\mathrm{B}_{1} \mathrm{X}_{1}+\mathrm{B}_{2} \mathrm{X}_{2}+\ldots+\mathrm{B}_{11} \mathrm{Y}_{1}^{2}+\mathrm{B}_{22} \mathrm{X}_{2}^{2}+\ldots . .+\mathrm{B}_{12} \mathrm{X}_{1} \mathrm{X}_{2}+\mathrm{B}_{13} \mathrm{X}_{1} \mathrm{X}_{3}+\mathrm{B}_{23} \mathrm{X}_{23}+\ldots \ldots$

\section{2-2 Estimation of the parameters : -}

Suppose data for multiple linear regressions as:-

\begin{tabular}{|c|c|c|}
\hline $\mathrm{Y}$ & $\mathrm{X}_{1}$ & 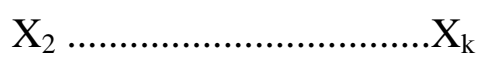 \\
\hline $\mathrm{Y}_{1}$ & $\mathrm{X}_{11}$ & $\mathrm{X}_{12} \ldots \ldots \ldots \ldots \ldots \ldots \ldots \ldots \ldots \ldots \ldots \ldots \ldots \ldots$ \\
\hline $\mathrm{Y}_{2}$ & $\mathrm{X}_{21}$ & f................ \\
\hline$Y_{n}$ & $\mathrm{X}_{\mathrm{n} 1}$ & $\mathrm{X}_{\mathrm{n} 2} \ldots \ldots \ldots \ldots \ldots \ldots \ldots \mathrm{X}_{\mathrm{nk}}$ \\
\hline
\end{tabular}

Table (1)(Data regression model)

We assume the error term $(\varepsilon)$ in the model has.

$\mathrm{E}(\varepsilon)=\mathrm{o}$ and $\operatorname{Var}(\varepsilon)=62$ and that the $(\varepsilon \mathrm{i})$ are un correlated random variables.

Then

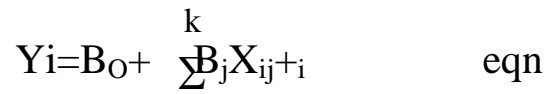

$$
\begin{aligned}
& , i=1,2, \ldots ., n \quad j=1
\end{aligned}
$$

The method of least squares chooses the B s so that the sum of squares of the errors ( $\varepsilon i$ ) is minimized.

$$
\sum_{i=1}^{n} \varepsilon^{2}
$$


$\mathrm{L}=$

$L=\sum_{i=1}^{n}\left(\begin{array}{ll}\text { yi-bo- } & \text { Bj Xij })\end{array}\right.$

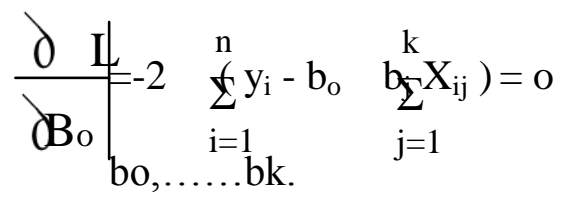

And

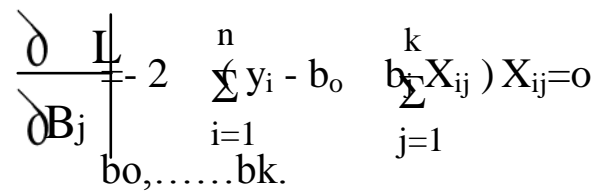

Then

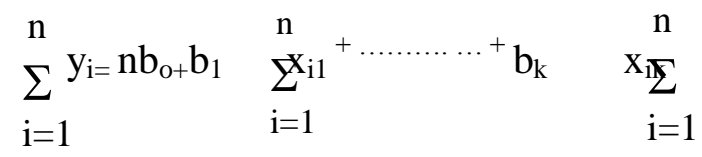

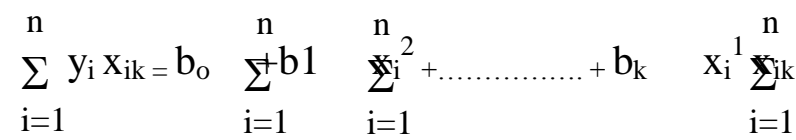

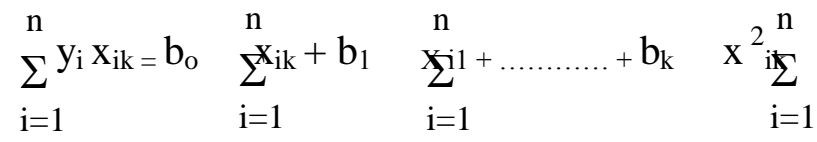

Then we expressed the equations in the matrix notation:-

$$
\mathrm{Y}=\mathrm{XB}+\square
$$

Where:-

$$
\mathrm{Y}=\left[\begin{array}{c}
\mathrm{Y} 1 \\
\cdot \\
\cdot \\
\mathrm{Yn}
\end{array}\right] \mathrm{X}=\left[\begin{array}{ccc}
\mathrm{I} & \mathrm{x} 11 \ldots \ldots \ldots \mathrm{x} 1 \mathrm{k} & \\
\mathrm{I} & \mathrm{x} 21 \ldots \ldots \ldots \mathrm{x} 2 \mathrm{k} & \mathrm{B} \\
\cdot & & \\
. & & \\
\mathrm{I} & \mathrm{xn} 1 \ldots \ldots \ldots \mathrm{xnk} &
\end{array}\right]
$$$$
\left[\begin{array}{l}
\mathrm{Bo} \\
\mathrm{B} 1 \\
\cdot \\
\mathrm{Bk}
\end{array}\right]
$$ 


$$
\text { And } \square=\left[\begin{array}{l}
\boldsymbol{\varepsilon}_{1} \\
\cdot \\
\cdot \\
\boldsymbol{\varepsilon}_{\mathrm{n}}
\end{array}\right]
$$

From equation (3) $\mathrm{L}=\sum_{\mathrm{i}=1}^{\mathrm{n}} \varepsilon_{1}^{2}$

Then

$\mathrm{L}=\square^{\prime} \square$

$L=(y-x B)^{\prime}(y-x B)$

$L=y^{\prime} y-B^{\prime} X^{\prime} Y-y^{\prime} X B+B^{\prime} X^{\prime} X^{\prime} B$

$L=y^{\prime} y-2 y X^{\prime} B^{\curlywedge}+B^{\prime} X^{\backslash} X^{\prime} B$

$\frac{\partial \mathrm{I}_{-}-2}{\partial \mathrm{B}_{\mathrm{b}} \mathrm{Y}+2 \mathrm{X}^{\prime} \mathrm{Xb}}$

$b=\left(X^{\prime} X\right)^{-1} X^{\prime} Y$

The filled regression model is:-

$\hat{Y}=\mathrm{Xb}$

Then the difference between the observation $Y_{i}$ and filled valve $\stackrel{\Lambda}{Y_{i}}$ Is a residual say

$$
\stackrel{\Lambda}{\mathrm{E}}=\mathrm{y}_{\mathrm{i}}-\mathrm{y}_{\mathrm{i}}
$$

\section{2-3 Experiments and methodology :}

\begin{tabular}{|l|l|l|l|}
\hline Factors & Level (1) & Level (2) & Level (3) \\
\hline Y: depth of out & $0.04 \quad$ (in) & 0.06 & 0.08 \\
\hline $\mathrm{X}_{2}:$ cutting speed & 1500 (r.p.m) & 2500 & 3500 \\
\hline
\end{tabular}




\begin{tabular}{|l|l|l|l|}
\hline $\mathrm{X}_{5}:$ feed rate & $20 \quad$ (in.p.m ) & 30 & 40 \\
\hline
\end{tabular}

Table (2) independent variables with levels

The data of (12) experiments : -

\begin{tabular}{|c|c|c|c|c|}
\hline $\begin{array}{c}\text { Experiment } \\
\text { numbers }\end{array}$ & $\mathrm{X}_{1}$ & $\mathrm{X}_{2}$ & $\mathrm{X}_{3}$ & Surface roughness $((\mu \mathrm{in})$ \\
\hline 1 & 0.04 & 1500 & 20 & 20.15 \\
\hline 2 & 0.04 & 2500 & 30 & 20.23 \\
\hline 3 & 0.04 & 3500 & 40 & 21.5 \\
\hline 4 & 0.04 & 1500 & 30 & 22.62 \\
\hline 5 & 0.06 & 2500 & 40 & 24.72 \\
\hline 6 & 0.06 & 3500 & 20 & 24.35 \\
\hline 7 & 0.06 & 1500 & 40 & 23.32 \\
\hline 8 & 0.06 & 2500 & 20 & 24.98 \\
\hline 9 & 0.08 & 3500 & 30 & 20.25 \\
\hline 10 & 0.08 & 1500 & 20 & 21.25 \\
\hline 11 & 0.08 & 2500 & 40 & 22.11 \\
\hline 12 & 0.08 & 3500 & 30 & \\
\hline
\end{tabular}

Using Matlab :-

$\mathrm{b}=\left(-14.11 ; 1030 ;-0.0065 ; 0.94 ;-8601.1 ;-1.2441 \times 10^{-7} ;-0.012 ; 0.075 ;-5.31\right.$; $\left.8.0559 \times 10^{-5}\right)$

$\Lambda$

$\mathrm{Y}=(20.15,21.23,21.329,22.791,25.232,21.691,24.489,22.808,23.46,20.321,21.25$,

$23.46)$

and

$\mathrm{E}=\mathrm{Yi}-\mathrm{Yi}=(0.00,0.00,0.171,-0.171,-0.512,-0.341,0.341,-0.512,1.52$,

$-0.171,0.00,-1.53)$

\section{3- Simulated Annealing Algorithms ( SAA )}

The SAA mimics the cooling phenomenon of the molten metals to constitute a search procedure. In the molten state the atoms in the liquid metal have high energy and so unstable and move freely with respect to each others. When the liquid metals solidified by cooling the atoms loose their energy through reduction of heat and temperature stop their movement becomes stable and form orderly structure knows as crystals .Hence in the solid state the atoms in the metal are at low energy level. However their energy level and so the type of crystal structure (such as body centered cubic of face centered cubic) depend on the cooling rate at which the metal is solidified(2)

Slower the cooling rate more stable is crystals with atoms in low energy states at the room temperature this process of slow cooling of metals into solid is known as annealing in metallurgical parlance. SAA simulate the metallurgical annealing process in its search mechanism

It adopt the Boltzmann probability distribution which says a system in thermal equilibrium at a temperature $\mathbf{T}$ has its energy distributed probability according 
to : $\quad \mathrm{P}(\mathrm{E})=\mathrm{EXP}(-\mathrm{E} / \mathrm{KT})$

Where $\mathbf{k}$ is the BOLTZMANN constant (1)

This means that a system at high temperature has almost uniform probability of being at any energy state. But at low temperature it has small probability of being at high temperature state SAA states with an initial point Xi (a feasible solution) and at high initial temperature $\mathbf{T}$ A second solution $\mathrm{Xi}+1$ (other solution) is created at random in the neighborhood of the initial point and their difference in the (objective) function value.(4)

$\Delta \mathrm{E}=\mathrm{E}(\mathrm{xi}+1)-\mathrm{E}(\mathrm{Xi})$

Is calculated. If $\Delta<_{0}$ the second point is better than the initial point (in the case of minimization objective function). And hence is accepted.

Otherwise the accepted with probability of $\exp (\Delta \mathrm{E} / \mathrm{KT})$ i.e. as per the Boltzmann probability low, the probability of acceptance of an interior solution is more at higher temperature $\mathbf{T}$ and less at lower temperature $\mathbf{T}$.(2)

This Completes an iteration of the simulated annealing procedure. In the next generation another points is created at random in the neighborhood of the current point and the metropolis algorithm is used to accept or reject the point. In order to simulate the thermal equilibrium at every temperature a number of point (Np)are usually tested ,

at a particulate temperature before reducing the temperature. The algorithm is terminated when a sufficiently small temperature is obtained or a negligible change in function values is found.(6)

\section{3-1 Code of SA algorithm (5)}

Step 1: choose an initial point Xo , termination criterion $\square$, number of titration to be performed at particular temperature

$(\mathrm{Np})$ set $\mathrm{T}$ a sufficiently high value and set $\mathrm{I}=\mathrm{o}$

Step 2: $\quad$ calculate neighborhood point $\mathrm{Xi}+1 \mathrm{C} \mathrm{N}(\mathrm{Xi})$ 
Step 3: $\quad$ if $\Delta \mathrm{E}=\mathrm{E}(\mathrm{xi}+1)-\mathrm{E}(\mathrm{Xi})<\mathrm{o}$

set $\mathrm{I}=\mathrm{I}+1$

else:

create a random number $(\mathrm{Rn})$ in range $(0,1)$

if : $\quad \Delta \mathrm{E}=\mathrm{E}\left(\mathrm{X}_{\mathrm{i}+1} 1\right)-\mathrm{E}\left(\mathrm{X}_{\mathrm{i}}\right)<0$, set $\mathrm{I}=\mathrm{I}+1$,

else :

end if

$$
\text { go to step } 2
$$

end if

end do

Step 4 if $\Delta \mathrm{E}$ and / or $\mathrm{T}$ is small terminate else:

Lower $\mathrm{T}$ according to cooling schedule go to step 2

end if go to step 2

Then

Objective function is :-

$\mathrm{Y}=-14.11+1030 \mathrm{X}_{1}-0.0065 \mathrm{X}_{2}+0.94 \mathrm{X}_{3}-8601.1 \mathrm{X}_{1}^{2}-1.2441 \mathrm{X}_{10}{ }^{-2} \mathrm{X}_{2}^{2}-$

$0.012 \mathrm{X}_{3}^{2}+0.075 \mathrm{X}_{1} \mathrm{X}_{2}-5.31 \mathrm{X}_{1} \mathrm{X}_{3}+8.0559 \mathrm{X}_{10}{ }^{-5} \mathrm{X}_{2} \mathrm{X}^{3}$

Subjected to : -

$0.04 \leq \mathrm{X}_{1} \leq 0.08$

$1500 \leq \mathrm{X}_{2} \leq 3500$

$20 \leq \mathrm{X}_{3} \leq 40$

And $X_{1} \cdot X_{2} \cdot X_{3} \geq 0$

Then we use simulated annealing algorithms to solve this problem obtained from RSM to predict the best result of surface roughness. 


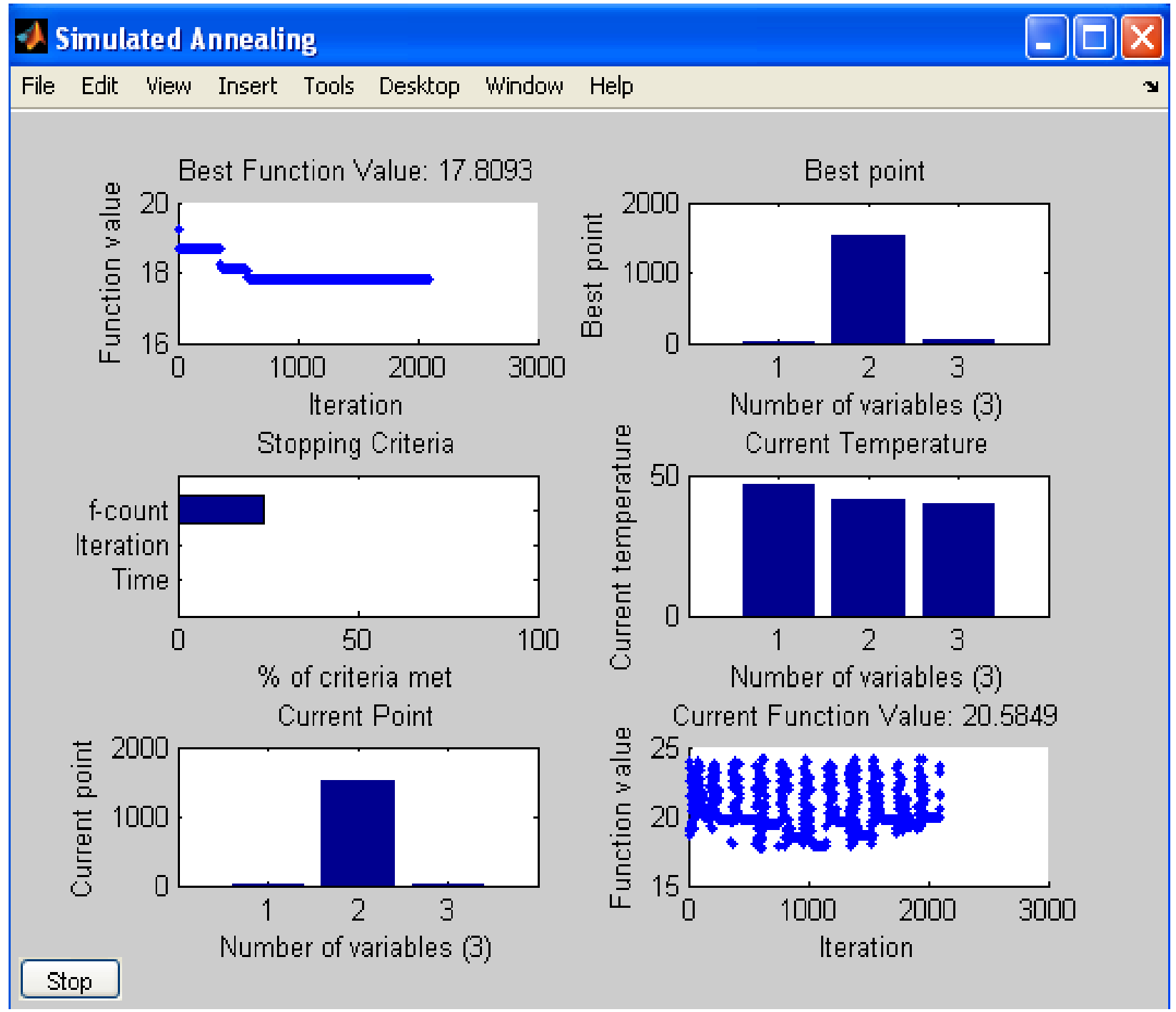

Figure (1): Simulated Annealing Matlab Graphs. 


\section{(4)Result}

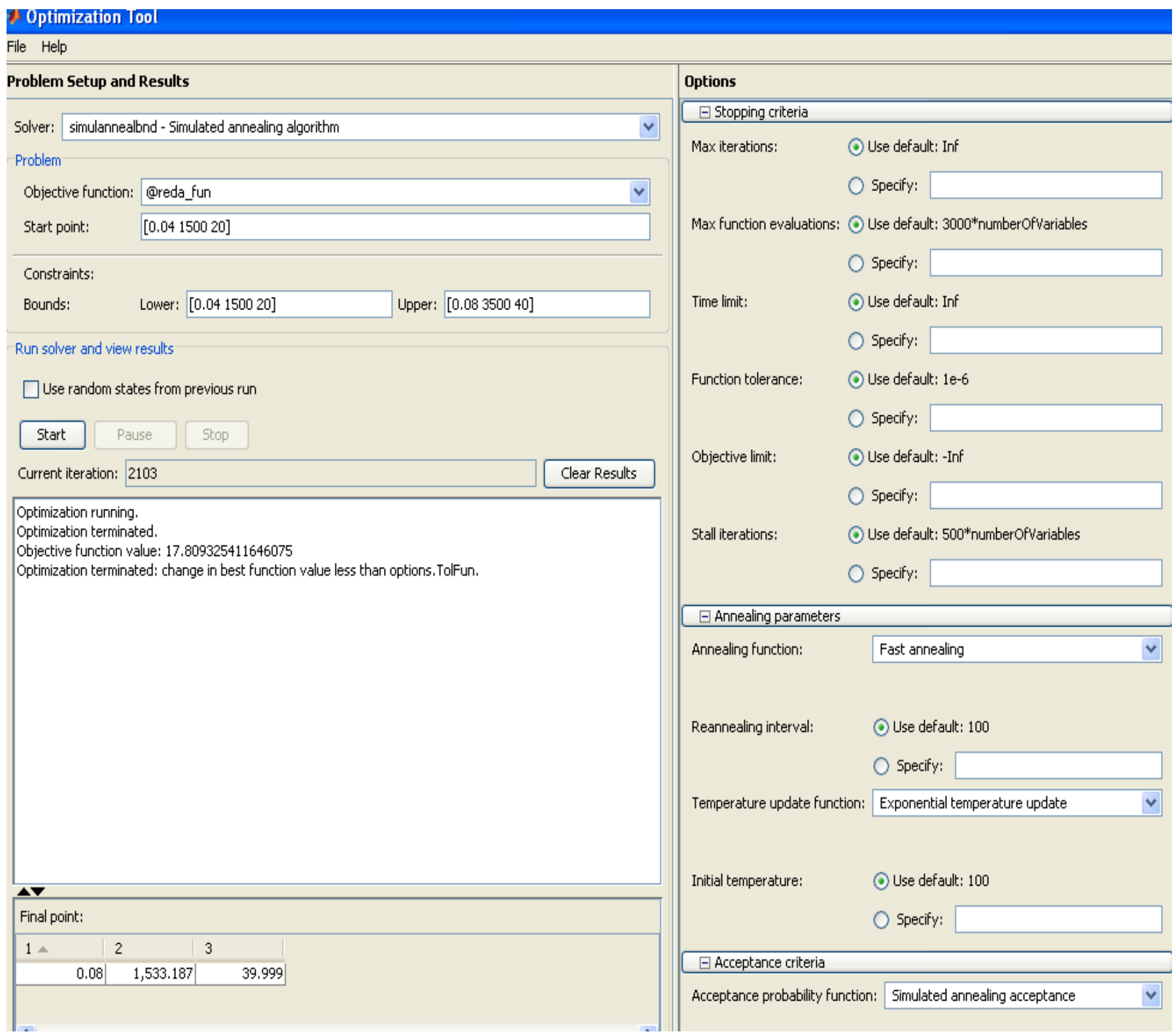

Figure (2): Simulated Annealing Matlab Result. 


\section{(5) Conclusion}

In this paper we use RSM in combination with Simulated Annealing to Optimization of EndMilling Operation the result:-

Surface roughness $=17,809325411646075 \mu$ in

And final optimal point:-

1- Depth of cut $=0.08$ in.

2- Cutting speed $=1533.187$ r.p.m

3- Feed rate $=39.999$ in.p.m

RSM may not be accurate enough in modeling highly nonlinear behaviors as this process and also the improvements to the accuracy of the RSM are limited

Then when we study SAA in combination with RSM, we obtained accurate result near the optimum solution.

\section{(6) References}

(1) Aarts. E .. and J. Korst 1989. simulated annealing and Boltzman Machines New York: John Wiley and son.

(2) Bohachevsky , I.O.,M.E.Johnson,and M.L Stein.1986.Generalized Simulated Annealing for function Optimization. Technometrics.

(3) Box, G.E.P., and N.R Draper.1987.Empirical Model-Building and Response Surfaces. New York:John Wiley and Sons

(4) Brown, D.E.,C.L. Pittard and D.E. sappington 1993. SPA: Sensor Placement Analyzer, An Approach to the Sensor Placement Problem . Institute for Parallet Computation, Department of Systems Engineering, University of Virginia Charlottesville, Virginia

(5) Brown D.E., Simulated Annealing In Linear Programming, J.P. Ignizo and T.M. Cavalier.New Jersey:Prentice-Hall.

(6) Brown,D.E., and J.B. Scamburg.1997. A Simulation Systems, IEEE Conference on Computational Cybernetics and Simulation .

(7) Ignizio, J.. P., and T.M.Cavalier. 1994. Linear Programming . New Jersey : PrenticeHall Schamburg,J.B. 1995 Deployment Planning and Analysis for Time Difference of Arrival and Differential Doppler Loation Finding Assets , Thesis , University of Virginia, Charlottesville, Virginia. 